Open Access

\title{
Does affirmative action in Chinese college admissions lead to mismatch? Educational quality and the relative returns to a baccalaureate degree for minorities in China
}

\author{
Sai Ding ${ }^{1 *}$, Samuel L. Myers $\mathrm{Jr}^{2}$ and Gregory N. Price $^{3}$
}

\author{
* Correspondence: \\ dingsai@cass.org.cn \\ ${ }^{1}$ Institute of Ethnology and \\ Anthropology, Chinese Academy of \\ Social Sciences, Bldg. 6/27, \\ Zhongguancun, Nandajie, Beijing \\ 10081, People's Republic of China \\ Full list of author information is \\ available at the end of the article
}

\begin{abstract}
This paper utilizes data from the 2002 Chinese Household Income Project to estimate the labor market return to graduating from college relative to high school. Parameter estimates of heterogeneous treatment effects reveal that for minorities, the average treatment effect of earning a baccalaureate degree from colleges/universities ranked good and very good is high relative to the Han majority, and for those actually receiving the treatment from colleges/universities ranked good. Our findings suggest that the mismatch hypothesis cannot be viewed as a universal phenomenon that renders affirmative action in college/university admissions an ineffective policy tool to redress/remedy historic discrimination against minority groups.
\end{abstract}

Keywords: College education, Heterogenous treatment effects, Chinese minority groups JEL classification: C21, 124, 125, J15, J24, 053, Z13

\section{Background}

Much discussion concerning the efficacy of affirmative action in college and university admissions focuses on the United States. This paper offers a unique perspective by examining the effects of affirmative action on ethnic minority earnings in China. There are 55 ethnic minority groups in China that constitute approximately $9 \%$ of the population. Despite post-1978 reform efforts to modernize the economy, most evidence suggests that ethnic minorities lag behind the Han majority in educational attainment (Myers et al. 2013). In her consideration of how educational attainment in China is stratified by ethnicity, Hannum (2002) indicates that one reason why an ethnic minority relative to Han majority educational attainment disparity exists may be due to ethnic minority groups perceiving that the tangible returns to education may be low. Of course, to the extent that there is ethnic minority discrimination in China's labor market (Johnson and Chow 1997; Li 2003; Zang 2008) that lowers the return to investment in human capital, then relative to the Han majority, members of China's 55 officially recognized ethnic groups would have an incentive to invest less in human capital. To

(c) The Author(s). 2017 Open Access This article is distributed under the terms of the Creative Commons Attribution 4.0 International License (http://creativecommons.org/licenses/by/4.0/), which permits unrestricted use, distribution, and reproduction in any medium, provided you give appropriate credit to the original author(s) and the source, provide a link to the Creative Commons license, and indicate if changes were made. 
redress these educational disparities, China initiated deliberate affirmative action policies designed to reduce ethnic economic inequality (Mishra and Smyth 2010; Zang 2008). Some argue, however, that these policies have the unintended effect of reducing optimal investment in human capital and thus thwart efforts to reduce Han-Minority disparities in education and earnings. This is similar to arguments often made for the poor educational outcomes for African Americans in the face of affirmative action in the United States (Fryer et al. 2005).

The challenge to understanding how or whether affirmative action retards or enhances ethnic disparities in China is that relative disadvantange or ethnic minorities manifests itself in multiple forms. There are disadvantages in education completion (Hannum 2002; Rong and Shi 2001; Wu 2010), health (Elu and Price 2013), the labor market (Becquelin 2000; Hannum and Xie 1998; Li and Ding 2013; Maurer-Fazio et al. 2010; Jijiao and Peng 2013; Yee 2003; Zang 2008), the incidence of poverty (Gustafsson and Ding 2009a), and in living standards (Gustafsson and Ding 2009b). With respect to labor market earnings, Johnson and Chow (1997), Li (2003), and Xiaowei and Lulu (2001) find evidence of minority-Han majority differentials that is suggestive of discrimination against minorities in the post-reform era.

Another challenge to understanding the effects of affirmative action in China is that quality of institutions vary substantially from one province to another. Most of the top universities in China are located in Beijing and Shanghai, the largest cities in the nation. ${ }^{1}$ But, regional universities as well as Minzu (minority) Universities are often the destination for students with lower test scores. Thus, there is a sorting mechanism produced by affirmative action in a nation where there is a single criterion for admission to college: the national test score. ${ }^{2}$ The primary route for implementation of affirmative action in higher education in China is via additional points awarded to ethnic minority group members on their Gao Kao scores. ${ }^{3}$

Gao Kao (The National College Entrance Examination) is organized by the Ministry of Education of the People's Republic of China. Beijing, Shanghai and the other thirteen provinces, howver, use their own examination questions. ${ }^{4}$ The Gao Kao scores are almost the only evidence universities use to matriculate students. The Chinese government ranks colleges and universities and have identified the "top" or very good instituions as well as the next tier of (or good) institutions both for receipt of funding and for national recognition. These top insittuions are identified as "985" program and "211" program universities. ${ }^{5}$ The admissions standards at these top program universities nationwide always are higher than the admissions for other, often regional instituions. For example, Beijing University - sometimes called the Harvard of China designated the minimum admission score for science students from Yunnan Province in 2015 to be 699 out of a total score of 750. Yunnan Province is located in the heavily minority area of southwest China and has both a minority university (Yunnan Minzu University, formerly Yunnan University for Nationalities) and a conventional although not highly ranked regional institution, Yunnan University. The designated minimum admission scores for science students from Yunnan in 2015 was only 530 at Yunnan University and 489 at Yunnan Minzu University. ${ }^{6}$

Officially recognized members of ethnic minority groups can receive from five to up to 50 extra points on their Gao Kao scores. The extra points awarwded vary from province to province and not every province awards points for all 55 ethnic minority 
groups. For example, Inner Mongolia - an ethnic minority autonomous region dominated by the ethnic minority group, Mongolians - only awards extra points to Mongolian, Daur, Oroqen, Evenki and Russ students. Other minority students are not eligible for the additional points.

In short, China has a very explicit form of affirmative action that acts as a point system similar to the price premia and point systems often struck down as unconstitutional in the United States. Embedded in the system is the potential for alleged "mismatch" since minority students with say 650 initial scores might matriculate at top universities where they are in the lower tier of their peers or they might matriculate at regional universitis where they would be at the very top of their classes. In this sense, then, China is a good test for the mismatch hypothesis as well as the view that affirmative action reduces investment in human capital and reduces relative earnings of minorities.

The remainder of the paper is organized as follows. In Section II the data and empirical methodology are discussed. Our econometric strategy for identifying the relative minority to Han majority returns to 4 years of college views the receipt of a baccalaureate degree as a heterogeneous treatment with selection. In particular we view being a minority with a baccalaureate degree in China as a source of heterogeneous outcomes in the labor market. We report parameter estimates in section III, and the last section concludes.

\section{Methods}

As in Heckman and Li (2004), we consider a potential outcomes specification of a Mincerian earnings equation of the form $\ln Y_{i}=\beta_{i} S_{i}+\gamma X_{i}+U_{i}$, where $Y_{i}$ is a measure of earnings, $S_{i}=1$ for individuals with a baccalaureate degree and $S_{i}=0$ if an individual is a high school graduate, $\beta_{i}$ is the heterogeneous return to education, $X_{i}$ is a vector of conditioning variables with effects given by the vector $\gamma$, and $U_{i}$ is an error term. Given the two potential outcomes $\ln Y_{i}=S_{i} \ln Y_{1 i}+\left(1-S_{i}\right) \ln Y_{0 i}, U_{i}=S_{i} U_{1 i}+\left(1-S_{i}\right) U_{0 i}$, and individuals select going to college or not according to $S_{i}^{*}=f(Z), S_{i}=1$ if $S_{i}^{*} \geq 0$, where $S_{i}^{*}$ is a latent variable capturing the net benefit of an individual earning a baccalaureate degree, and $Z$ is a vector of variables that determine $S_{i}^{*}$.

Given the treatment $S_{i}$, three treatment effects can be defined and estimated: 1.) The Average Treatment Effect (ATE), 2.) The Average Treatment Effect on the Treated (ATET), and 3.) The Average Treatment Effect on the Non-Treated (ATENT). For $S_{i}=1$, ATE measures the treatment effect for a randomly selected member of the population and ATET measures the treatment effect for those who actually received the treatment. ATENT measures the treatment effect on those who did not receive the treatment had they in fact received the treatment. ${ }^{7}$ If there is selection into treatment and treatment effects are heterogeneous such that individual characteristics in $X_{i}$ condition outcomes, then in general $\operatorname{ATE} \neq \operatorname{ATE}\left(X_{i}\right), \operatorname{ATET} \neq \operatorname{ATET}\left(X_{i}\right)$ and $\operatorname{ATENT} \neq \operatorname{ATENT}\left(X_{i}\right){ }^{8}$

The treatment effect of interest in this paper measures the causal effect of an individual's decision to earn a baccalaureate degree within the Rubin Causal Model (RCM) framework (Holland 1986). In the RCM framework, a treatment effect is defined for each individual in terms of two potential outcomes. Each individual has one outcome that would manifest if exposed to the treatment of earning a baccalaureate degree from 
a Chinese college/university of a given quality, and another outcome if were exposed to the control of not having earned a baccalaureate degree at all. The treatment effect is the difference between these two potential outcomes. Given evidence of heterogeneity in the returns to education in Asia (Tsai and Xie 2011), our heterogeneous treatment effect estimates enable better identification of the returns to education when there is selection on both observables and unobservables that are specific to ethnicity. In this context, our estimates of the relevant treatment effect constitutes an evaluation of educational policies in China that aim to enhance college/university access for minorities, as well as informing the labor market rate of return on an earned baccalaureate degree conditional upon the quality of the college/university.

We utilize data from the 2002 CHIPS (Li 2002). In particular, we use the Urban Individual Income, Consumption and Employment Data, as it enables estimation of earnings equations in the large Chinese urban labor market. ${ }^{9}$ The 2002 CHIPS was designed and implemented to measure and estimate the distribution of personal income and related economic factors in both rural and urban areas of the People's Republic of China. The measures of earnings are based on cash payments and on a broad range of additional components. The Urban Individual Income, Consumption and Employment Data provides standard demographic variables such as the individual's ethnicity, as well as economic variables such as medical insurance and expenditures, economically productive social contacts, and employment information including occupation, sector, income, hours, conditions, job history, and training. All data were collected through a series of questionnaire-based interviews conducted in rural and urban areas at the end of 2002.

While there are several waves of CHIPS, which would enable larger estimation samples, we constrain our analysis to the 2002 CHIPS as it permits an identification strategy not possible otherwise. ${ }^{10}$ Given that individual schooling choices are potentially correlated with unobservables, unbiased parameter estimation with selection on unobservables requires an instrument and exclusion restriction on a covariate that is uncorrelated with individual unobservables. The 2002 CHIPS contains a covariate, not present in other sample years of CHIPS, that enables identification in the presence of selection on unobservables. In particular, the 2002 CHIPS identifies whether or not an individual respondent was an "intellectual youth" meaning the respondent moved to the rural areas during the Cultural Revolution.

Our interest in the intellectual youth variable stems from its utility as in input into a sensible identification strategy. Li and Zax (2003) suggest that Chinese workers who were rusticated in their youth and sent to rural areas during the Cultural Revolution suffered in both the quality and the quantity of their education. As our inquiry explores the effects of minority group status on both the returns and returns by quality of a baccalaureate degree, that being an intellectual youth can condition schooling decisions enables identification of baccalaureate degree treatment effects.. To the extent that moving to rural areas during the Cultural Revolution is plausibly unrelated to labor supply preferences as Li and Zax (2003) posit, it is likely to be uncorrelated with unobservables such as ability that is related to individual schooling investment decisions. As such, having been an intellectual youth can serve as an exclusion restriction for identifying the returns to schooling when there are both observables and unobservables that govern selection into college. 
Our strategy to determine if the returns to a baccalaureate degree are different between minorities and the Han majority is to determine if ethnicity is a source of heterogeneity in the labor market returns to a baccalaureate degree. The same strategy is adopted for the returns to a baccalaureate degree given the quality of the college/university from which the degree was earned. We specify and estimate a Mincerian earnings equation where $Y_{i}=$ annual earnings, and the elements of $X_{i}$ include, years of labor market experience, a binary indicator for being male, a binary indicator for being a member of the communist party, a binary indicator for being employed in the manufacturing sector, a binary indicator for being employed in a state-owned enterprise. ${ }^{11}$ To control for earnings differences due to ethnic minority educational stratification by geography (Hannum and Meiyan 2006), we also include binary controls for the 11 different provinces respondents reported in the 2002 CHIPS. We consider three treatments $\left(S_{i}\right)$ : Graduated from college, Graduated from a college ranked very good, and Graduated from a college ranked good. All covariates are derived from relevant questions from the Urban Individual Income, Consumption and Employment Data in the 2002 CHIPS, for which a summary is reported in Table 1.

Table 1 Covariate summary

\begin{tabular}{|c|c|c|c|}
\hline Variable & Mean & Standard deviation & Number of observations \\
\hline Annual earnings $^{a}$ & $10,663.54$ & 8296.35 & 3779 \\
\hline Years of labor market experience & 19.47 & 8.79 & 3779 \\
\hline Male ${ }^{b}$ & .559 & .486 & 3779 \\
\hline Member of communist party ${ }^{\mathrm{b}}$ & .291 & .454 & 3779 \\
\hline Employed in manufacturing sector ${ }^{\mathrm{b}}$ & .242 & .428 & 3779 \\
\hline Employed in state-owned enterprise ${ }^{b}$ & .321 & .467 & 3779 \\
\hline Graduated from college $\mathrm{e}^{\mathrm{b}}$ & .255 & .436 & 3779 \\
\hline Graduated from college ranked very good ${ }^{b}$ & .039 & .194 & 2930 \\
\hline Graduated from college ranked good ${ }^{b}$ & .102 & .303 & 3136 \\
\hline Minority $^{b}$ & .034 & .181 & 3779 \\
\hline Intellectual youth ${ }^{\mathrm{b}}$ & .171 & .376 & 3779 \\
\hline Anhui Province ${ }^{b}$ & .070 & .256 & 3779 \\
\hline Beijing Province $^{b}$ & .086 & .281 & 3779 \\
\hline Chongqing Province $^{\mathrm{b}}$ & .046 & .209 & 3779 \\
\hline Gansu Province $e^{b}$ & .064 & .244 & 3779 \\
\hline Guangdong Province ${ }^{b}$ & .108 & .311 & 3779 \\
\hline Henan Province ${ }^{b}$ & .104 & .306 & 3779 \\
\hline Hubei Province ${ }^{b}$ & .099 & .298 & 3779 \\
\hline Liaoning Province & .101 & .301 & 3779 \\
\hline Shanxi Province ${ }^{b}$ & .089 & .285 & 3779 \\
\hline Sichuan Province ${ }^{b}$ & .068 & .252 & 3779 \\
\hline Yunnan Province ${ }^{\mathrm{b}}$ & .067 & .251 & 3779 \\
\hline
\end{tabular}

Source: 2002 Chinese Household Income Project Series

${ }^{a}$ Annual earnings (Yuan) is defined as Total income less the sum of bonuses, allowance/subsidies, price subsidies, local subsidies, living hardship subsidies, and subsidies for minimum living standard ${ }^{\mathrm{b}}$ Binary/dichotomous indicator 


\section{Results and Discussion}

Table 2 reports the relevant treatment effects. High School graduates are the control group. The results in the first column assume no selection into a homogeneous treatment and are based on an Ordinary Least Squares (OLS) specification of $\ln Y_{i}$. The second column assumes selection into a homogeneous treatment. The last three columns assume selection into a heterogeneous treatment, where the heterogeneity is conditioned on whether on not an individual is a member of ethnic group. ${ }^{12}$ Given that the ATE is no longer a singleton when there is heterogeneity and selection in treatment outcomes, we report the ATE, ATET and ATENT when conditioning on an individual's minority status. With the exception of the treatment parameter estimates with heterogeneity conditioned on minority status reported in the last three columns, the specifications are estimated with the person-level weights.

As the decision to attend college is potentially correlated with unobservables, we instrument our measure of college graduation with a binary variable indicating whether or not the respondent was an "intellectual youth" meaning the respondent moved to the rural areas during the Cultural Revolution. In particular, we use the intellectual youth binary variable as an exclusion restriction in a Heckit two-step estimator of treatment effects. ${ }^{13}$ We use a bootstrap (Efron and Tibshirani 1993) with 100 replications in all the Heckit IV heterogeneous treatment specifications to estimate the standard errors for the treatment effects. ${ }^{14}$

Table 2 The returns to a baccalaureate degree for minorities in China treatment effect parameter estimates

\begin{tabular}{|c|c|c|c|c|c|}
\hline & $\begin{array}{l}\text { ATE } \\
\text { (OLS) }\end{array}$ & $\begin{array}{l}\text { ATE } \\
\text { (Heckit) }\end{array}$ & $\begin{array}{l}\text { ATE } \\
\text { (Heckit|Minority) }\end{array}$ & $\begin{array}{l}\text { ATET } \\
\text { (Heckit|Minority) }\end{array}$ & $\begin{array}{l}\text { ATENT } \\
\text { (Heckit|Minority) }\end{array}$ \\
\hline \multicolumn{6}{|l|}{ Treatment effect: } \\
\hline \multicolumn{6}{|l|}{$\begin{array}{l}\text { Outcome: Log of annual } \\
\text { earnings }\end{array}$} \\
\hline \multicolumn{6}{|l|}{$\begin{array}{l}\text { Control group: high school } \\
\text { graduates }\end{array}$} \\
\hline \multicolumn{6}{|l|}{ Treatment: } \\
\hline Graduated from college & $.426(.026)^{a}$ & $.322(.145)^{b}$ & $.394(.188)^{b}$ & $.362(.246)$ & $.405(.172)^{b}$ \\
\hline Minority & $-.044(.062)$ & $-.067(.059)$ & $-.094(.084)$ & $-.094(.084)$ & $-.094(.084)$ \\
\hline$\lambda$ & & $.052(.085)$ & $.033(.226)$ & $.033(.226)$ & $.033(.226)$ \\
\hline Numberof observations: & 3779 & 3779 & 3779 & 3779 & 3779 \\
\hline $\begin{array}{l}\text { Graduated from college: } \\
\text { (Rank = very good) }\end{array}$ & $.452(.073)^{a}$ & $.713(.298)^{b}$ & $.827(.283)^{b}$ & $.104(.513)$ & $.857(.288)^{b}$ \\
\hline Minority & $-.038(.079)$ & $-.071(.090)$ & $.394(.430)$ & $.394(.430)$ & $.394(.430)$ \\
\hline$\lambda$ & & $-.155(.145)$ & $-.149(.263)$ & $-.149(.263)$ & $-.149(.263)$ \\
\hline Number of observations: & 2930 & 2930 & 2930 & 2930 & 2930 \\
\hline $\begin{array}{l}\text { Graduated from college: } \\
\text { (Rank = Good) }\end{array}$ & $.452(.038)^{a}$ & $.456(.169)^{b}$ & $.533(.183)^{b}$ & $.695(.313)^{\mathrm{b}}$ & $.514(.174)^{\mathrm{b}}$ \\
\hline Minority & $-.042(.074)$ & $-.082(.076)$ & $-.100(.077)$ & $-.100(.077)$ & $-.100(.077)$ \\
\hline$\lambda$ & & $.004(.088)$ & $.111(.237)$ & $.111(.237)$ & $.111(.237)$ \\
\hline Number of observations: & 3136 & 3136 & 3136 & 3136 & 3136 \\
\hline
\end{tabular}

Standard errors in parentheses

${ }^{\mathrm{a}}$ Significant at the .01 level

bignificant at the .05 level 
Given our interest in the treatment effect of having a college degree in China and how it may vary according to minority group status, for sake of economy and brevity in the exposition of results, the parameter estimates in Table 2 omit the estimated signs on the control covariates summarized in Table 1, in addition to the estimated parameters of the relevant selection into the relevant treatment specification. Beijing was excluded from the provincial dummies, enabling the 10 remaining provinces to identify the wage/earnings effects of being in a particular province relative to Beijing. We do report the estimated parameter for the minority indicator variable, and where relevant, the estimated parameter on the selection correction term $\lambda$. In total, the results in Table 2 follow from the estimated parameters of 15 regression, all of which except for the OLS results in the first column include a first-stage IV regression which being an intellectual youth is the instrument in the selection into treatment regression-which is excluded from the specification determining earnings.

The simple Ordinary Least Squares (OLS) ATE results in the first column suggest that for both ethnic minorities and the Han-majority, the labor market returns to a baccalaureate degree are substantial, and increase with the quality of the college/university granting the degree. As the return is relative to high school, the annual return is the estimated treatment effect-which is the change in annual earnings divided by the assumed 4 years spent earning a baccalaureate degree. The annual return for just having a baccalaureate degree is approximately $10.6 \%$, and this increases to approximately $11.3 \%$ and for graduating from a college/university ranked very good and good respectively. These estimates are approximately similar to those reported by Heckman and Li (2004), and provide further evidence of the hight returns to education in post-reform era Chinese labor markets.

Given selection into treatment, the ATE results in the second column reveal that for graduating from a college with a ranking of very good, the labor market returns to a baccalaureate degree are higher than estimated by simple OLS-which suggests that simple OLS estimates can be downwardly biased. ${ }^{15}$ The annual return for just having a baccalaureate degree is approximately $8 \%$, and this increases to approximately 17.8 and $11.4 \%$ for graduating from a college/university ranked very good and good respectively. The pattern of the selection-adjusted ATE estimate is similar to the OLS estimate, as the labor market return to a baccalaureate degree is increasing in the quality of the college/university from which the degree was earned.

The last three columns report selection-adjusted treatment effects allowing the labor market return for a baccalaureate degree to be conditioned on minority status. In particular, these parameter estimates allow for heterogeneity in the returns to a baccalaureate degree by allowing individuals a unique return that is a function of whether or not they are a minority. The ATE estimates reveal that for ethnic minorities, the labor market returns to a baccalaureate degree are lower, as for all three treatments, relative to the ATE estimates under homogeneity, minority status is associated with a higher ATE. For ethnic minorities, the annual return for just having a baccalaureate degree is approximately $9.9 \%$ for minorities. However this increases to approximately 20.1 and $13.3 \%$ for graduating from a college/university ranked very good and good respectively. For Chinese minorities actually receiving the treatment, the ATET results in column 4 are only significantly different from zero, in the case of a college/university ranked good. This suggests that relative to the Han majority that received the treatments, the 
returns to a baccalaureate degree are higher for minorities who graduate from a college/university ranked good.

As $\mathrm{ATE}=\mathrm{ATET} \times \operatorname{Prob}(\mathrm{S}=1)+\operatorname{ATENT} \times \operatorname{Prob}(\mathrm{S}=0)$, that the ATET is only significantly different from zero in the case of graduating from a college ranked good for all three treatments when conditioning on minority status provides insight into why relative to the Han majority, the ATET is no different in the case of graduating from college and graduating from a college ranked very good. The ATENT, which is not statistically significant for minorities for all three measures of earning a baccalaureate degree, is the labor market return the control group-minority high school graduates-would realize had they earned a baccalaureate degree. This suggests that one reason why the ATET conditioned on minority status is insignificant is not significant for all three measures is that colleges/universities have not fully exploited a pipeline of minority students who could earn and benefit from a baccalaureate degree. Indeed, to the extent that the ATENT is an increasing function of the number of high school graduates, the zero ATETs associated with earning a baccalaureate degree in general, and from a college/university ranked very good in particular for minorities could reflect a constrained supply of minority high school graduates that feed into China's colleges/ universities overall.

The estimated sign on the selection terms is never significant for the parameter estimates in columns $2-5$. This suggests that in general, the treatment of attending college is not endogenous, even when the returns are heterogeneous across ethnic groups in China. As the results do show that the returns are conditioned on minority status, one implication is that even if attending college is not endogenous, and correlated with individual unobservables, failure to control for heterogeneity due to minority group status could lead to biased estimates of the return to college in China as the OLS results in column 1 suggest.

The minority group status indicator is also never significant in the earnings equation. This suggests that being an ethnic minority is not a source of wage/earnings discrimination in China's urban labor markets. This runs counter to evidence of discrimination against urban minorities in China found by Ding et al. (2012) based on separate earnings specifications by gender. However, as the minority-specific treatment effects of having a college degree are always positive and significant, this suggests that minorities in China possibly offset wage/earnings discrimination through high educational investment relative to the Han majority (Wu 2012).

\section{Summary and conclusions}

Post-reform China educational policy has implemented an aggressive affirmative action college admissions policy for minorities (Zang 2008). This paper considers the extent to which such a policy has been effective, and if conditional on college/university quality, the labor market returns to a baccalaureate degree varies by ethnicity in China. ${ }^{16}$ Our inquiry permits an assessment as to how effective post-reform efforts have been at eradicating ethnic inequality through enhancing access to higher education. To the extent that the transition to a more market-oriented society increases the responsiveness of earnings to the quality of human capital (Zhong 2011; Li et al. 2012), our consideration of educational quality permits insight into whether or not in China, there is a 
labor market return to college/university quality (Long 2008, 2010), and if it differs between minorities and the Han majority.

We have used data from the 2002 Chinese Household Income Project Series (CHIPS) to estimate the labor market returns to graduating from college relative to high school. We allow for selection and heterogeneous returns by ethnicity, and estimate three treatment parameters that enable identification of the returns to a baccalaureate degree for minorities in China, and how it varies by the quality of the institution awarding the degree.

We estimated three treatment parameters that enable identification of the returns to a baccalaureate degree for minorities in China, and how it varies by the quality of the institution awarding the baccalaureate degree. Consistment with heterogeneity in the returns to education (Henderson et al. 2011) our estimate of treatment effects reveal that for minorities, the average treatment effect of earning a baccalaureate degree from colleges/universities ranked good and very good is high relative to the Han majority, and for those actually receiving the treatment from colleges/universities ranked good, and would be positive for those who could have earned a baccalaureate degree from colleges/universities ranked good and very good, but did not. Our results suggest that post-reform affirmative action education policies in China have been effective at improving the education and labor market outcomes of minorities. Estimates of the average treatment effect on the non-treated suggests that existing minority-Han disparities can be eliminated by further expanding the pipeline of minorities that complete high school and enter into colleges/universities that grant baccalaureate degrees.

Our results provide a useful alternative context for evaluating affirmative action in college/university admissions in the USA. We find, for example, that the relative return for minorities graduating from ranked universities is higher, and would also be for those who could have attended, but did not. This suggests that proponents of the mismatch hypothesis in the USA-the idea that at least some minority students who attend elite institutions in the USA would be better off in non-elite institutions-could be wrong. Our findings raise the possibility that, as in China, the relative returns to graduating from an elite university could be higher for minority groups in the USA, and that affirmative action in college/university admissions should be expanded so as to facilitate convergence in the returns to a baccalaureate degree between minority and majority groups.

Our inquiry provides a research perspective on how ethnicity and inequality intersect with public policy in China that can potentially inform how policy can address racedbased educational disparities elsewhere. In the USA, affirmative action in higher education has been controversial, with the presumed benefits and efficacy becoming increasingly questioned on empirical (Arcidiacono et al. 2011) and theoretical grounds (Fryer and Loury 2005). The results reported here provide some insight on how deliberate affirmative action policies in universities admissions can increase the return to college graduation in a country-China - that has a history of minority relative to majority ethnic group disparities in educational outcomes similar to the USA.

There are at least two limitations of our analysis. First, our results are based on a cross section of China's labor market in 2002. Since that time, the Chinese economy has grown substantially, and it is possible that in response to such growth, the pipeline of minorities into colleges/universities and the labor market has been enhanced in such a way the labor market returns on a baccalaureate degree for minorities has converged to that of the Han majority. As such, our findings could just be a transitory snapshot of 
a labor market that no longer exists. Second, our identification strategy imposes an exclusion restriction based on whether or not a respondent moved to the rural countryside during the cultural revolution. While the assumption that this instrument is uncorrelated with unobservables is untestable, the extent to which it is a good instrument could affect our Heckit estimates of the treatment effects. However, in all the Heckit estimates, the intellectual youth variable was negatively correlated with each measure of having earned a baccalaureate degree. This suggests that having moved to the countryside during the cultural revolution is correlated with observable schooling choices-earning a baccalaureate degree-that is not likely dependent upon unobservable preferences for schooling investment decisions.

The central contribution, however, of this paper is that it reveals the weakness in the so-called "mismatch hypothesis" underlying affirmative action. The mismatch hypothesis posits that a policy regime of affirmative action in college/university admissions increases the likelihood that a minority student is matched to a school that does not optimize her chances for success (Arcidiacono et al. 2011). Our results suggest that, at least in China, ethnic minority students admitted to colleges/universities under a policy regime of affirmative action fare better in the labor market relative to majority ethnic groups when earning a baccalaureate degree from high quality colleges/universities. This finding underscores a conceptual weakness in the mismatch contention and affirms that affirmative action in college/university admissions can be an effective policy tool to redress/remedy historic discrimination against minority groups.

\section{Endnotes}

${ }^{1}$ Some top Minzu Universities are also located in the largest cities, such as Beijing (Minzu University of China), Wuhan (South-Central University for Nationalities) and Chengdu (Southwest University for Nationalities) http://gkcx.eol.cn/soudaxue/quer yschool.html?\&keyWord1=\&schoolprop $=$ 民族类\&province $=\& 1=1$

${ }^{2}$ Ministry of Education, the People's Republic of China. 1990. Provisional regulations for senior secondary schools educational assessment. Beijing, China

${ }^{3}$ The decision of the State Council on Accelerating the Development of National Education,Ministry of Education of the People's Republic of China,Guo Fa [2015 ] No. 46

${ }^{4}$ http://learning.sohu.com/20150310/n409578725.shtml

${ }^{5}$ http://www.cdgdc.edu.cn/xwyyjsjyxx/xwbl/zdjs/985gc/index.shtml

${ }^{6} \mathrm{http}: / /$ college.gaokao.com/school/1/2015-06-10

${ }^{7}$ More specifically, ATENT measures the mean gain that the non-treated would have realized if they had been treated (Moffitt 1999).

${ }^{8}$ In general, conditioning the treatment effect on individual characteristics allows for an estimate of a conditional average treatment effect (Imai and Ratkovic 2013), in which the response to the treatment is idiosyncratic and/or subject to compositional effects (Tsai and Xie 2011; Xie 2013), which if ignored could lead to biased estimates of treatment effects.

${ }^{9}$ The 2002 Chinese Household Income Project consists of 10 datasets: 1.) Urban Individual Income, Consumption, and Employment Data, 2.) Urban Household Income, Consumption, and Employment Data, 3.) Urban Individual Annual Income Data 4.) Urban Household Assets, Expenditure, Income, and Conditions Data 5.) Village Administrative Data, 6.) Rural Individual Income, Consumption, and Employment 
Data, 7.) Rural Household Income, Consumption, Employment, Social Network, Quality of Life, and Village Affairs Data, 8.) Rural School-Age Children Data, 9.) Rural-Urban Migrant Individual Data, and 10.) Rural-Urban Migrant Household Data. We use the data compiled by the Inter-university Consortium for Political and Social Research (ICPSR) available at http://www.icpsr.umich.edu/icpsrweb/ICPSR/studies/21741.

${ }^{10}$ The 2002 CHIPS was administered by China's National Bureau of Statistics, and related to their household surveys, of which the methodology is described by Li et al. (2008).

${ }^{11}$ While political variables are not typically included in Mincerian earnings equations, we include a dichotomous indicator of Communist Party membership as there is evidence that it appears to matter for earnings in China (Li et al. 2007).

${ }^{12}$ Our parameterization of the heterogeneous treatment effects with selection into the treatment follow that of Cerulli (Cerruli 2014), where for outcome $y$ and treatment $w: E(y \mid \mathbf{x}, z, s)=\mu_{o}+\alpha w+\mathbf{x} \boldsymbol{\beta}_{\mathbf{o}}+w\left(\mathbf{x}-\boldsymbol{\mu}_{\mathbf{x}}\right) \boldsymbol{\beta}+\rho_{1} w[\phi(z \theta) / \Phi(z \theta)]+$ $\left.\rho_{o}(1-w)[z \theta) / 1-\Phi(z \theta)\right]$, where $\mu_{o}$ is the ATE, $s$ is the binary college graduation treatment, $z$ is a vector of variables determining selection into treatment, $\theta$ is the vector of coefficients for $z$, and $\phi(\cdot)$ and $\Phi($.$) are the density and cumulative$ normal distribution respectively. The relevant treatment parameters are: $\operatorname{ATE}(\mathbf{x})=$ $\alpha+\left(\mathbf{x}-\boldsymbol{\mu}_{\mathbf{x}}\right) \boldsymbol{\beta}, \operatorname{ATET}(\mathbf{x})=\left[\alpha+\left(\mathbf{x}-\boldsymbol{\mu}_{\mathbf{x}}\right) \boldsymbol{\beta}+\left(\rho_{0}+\rho_{1}\right) \times \lambda(z \theta) \mid w=1\right]$, and ATENT $=\left[\alpha+\left(\mathbf{x}-\boldsymbol{\mu}_{\mathbf{x}}\right) \boldsymbol{\beta}+\left(\rho_{0}+\rho_{1}\right) \times \lambda(z \theta) \mid w=0\right]$.

${ }^{13}$ We used a Stata module called IVTREATREG to estimate the treatment effects with selection and heterogeneity, which is available at http://ideas.repec.org/c/boc/bocode/ s457405.html. While IVTREATREG provides alternatives to Heckit to estimate treatment effects when the treatment is endogenous, Heckit permits estimation when both the binary treatment choices and outcomes depend upon a linear combination of both observable and unobservable factors.

${ }^{14}$ For the heterogeneous treatment specifications, we could not estimate the parameters with the household weights as STATA does not enable the use of sampling weights with bootstrapped standard errors. However, to the extent that bootstrapped standard errors enable consistent estimation of parameters given misspecification (Goncalves and White 2005) - in this the omission of sampling weights-bootstrap estimates of the treatment effects without the sampling weights can mitigate/eliminate the bias caused by the sample that may not be fully representative of the population of interest.

${ }^{15}$ Card (1999) posits that OLS estimates of the labor market returns to schooling are downwardly biased as a result of individuals with high discount rates choosing low levels of schooling, which have a higher marginal rate of return.

${ }^{16}$ Zang (2008) describes these post-1977 affirmative action policies as reflecting the desire of the Communist Party to promote inter-ethnic peace and political stability. With respect to college admissions, relative to the Han majority, minority students are admitted into colleges/universities with lower admission test scores. In addition, minorities are given a preference over the Han majority in hiring if they have similar or slightly lower qualifications.

Authors' contributions

SD is responsible for data collection and data cleaning; SLMJr. suggests the topic, GNP concentrates on the calculation. Three authors discussed together for the framwork and contents. All authors read and approved the final manuscript. 


\section{Publisher's Note}

Springer Nature remains neutral with regard to jurisdictional claims in published maps and institutional affiliations.

\section{Author details}

${ }^{1}$ Institute of Ethnology and Anthropology, Chinese Academy of Social Sciences, Bldg. 6/27, Zhongguancun, Nandajie, Beijing 10081, People's Republic of China. ${ }^{2}$ Humphrey School of Public Affairs, University of Minnesota, Minneapolis, Minnesota, USA. ${ }^{3}$ Department of Economics, Morehouse College, Atlanta, Georgia, USA.

Received: 10 August 2017 Accepted: 8 September 2017

Published online: 18 December 2017

\section{References}

Arcidiacono, Peter, Esteban M. Aucejo, Hanming Fang, and Kenneth I. Spenner. 2011. Does affirmative action lead to mismatch? A new test and evidence. Quantitative Economics 2: 303-333.

Becquelin, Nicolas. 2000. Xinjiang in the nineties. The China Journal 44: 65-90.

Card, David. 1999. "The causal effect of education on earnings." Handbook of labor economics 3: 1801-1863.

Cerruli, Giovanni. 2014. Ivtreatreg: A command for fitting binary treatment models with heterogeneous response treatment and unobservable selection. Stata Journal 14: 453-480.

Ding, Sai, Li, Shi Samuel L Myers Jr 2012. Intertemporal changes in ethnic urban earnings disparities in China. In Shi Li, Hiroshi Sato and Terry Sicular (Ed.), Rising inequality in China: Challenges to a harmonious society (pp. 414-444). New York: Cambridge University Press.

Efron, Bradley, and Robert J. Tibshirani. 1993. An introduction to the bootstrap. New York: Chapman and Hall.

Elu, Juliet U., and Gregory N. Price. 2013. Does ethnicity matter for access to childhood and adolescent health Capital in China? Evidence from the wage-height relationship in the 2006 China health and nutrition survey. Review of Black Political Economy 40: 315-339.

Fryer, Roland G., Jr., and Glenn C. Loury. 2005. Affirmative action and its mythology. Journal of Economic Perspectives 19: 147-162.

Fryer, Roland G., and Glenn C. Loury. 2005. "Affirmative action in winner-take-all markets." Journal of Economic Inequality 3: $263-280$.

Goncalves, Silvia, and Halbert White. 2005. Bootstrap standard error estimates for linear regression. Journal of the American Statistical Association 100: 970-979.

Gustafsson, Bjorn, and Sai Ding. 2009a. Villages where China's ethnic minorities live. China Economic Review 20: 193-207.

Gustafsson, Bjorn, and Sai Ding. 2009b. Temporary and persistent poverty among ethnic minorities and the majority in rural China. Review of Income and Wealth 55: 588-606.

Hannum, Emily. 2002. Educational stratification by ethnicity in China: Enrollment and attainment in the early reform years. Demography 39: 95-117.

Hannum, Emily, and Wang Meiyan. 2006. Geography and educational inequality in China. China Economic Review 17: 253-265.

Hannum, Emily, and Yu Xie. 1998. Ethnic stratification in Northwest China: Occupational differences between Han Chinese and ethnic minorities in Xinjiang, 1982 - 1990. Demography 35: 323-333.

Heckman, James J., and Xuesong Li. 2004. Selection bias, comparative advantage and heterogeneous returns to education: Evidence from China in 2000. Pacific Economic Review 9: 155-171.

Henderson, Daniel J., Solomon W. Polachek, and Le Wang. 2011. Heterogeneity in schooling rates of return. Economics of Education Review 30: 1202-1214.

Holland, Paul W. 1986. Statistics and causal inference. Journal of the American Statistical Association 81: 945-970.

Imai, Kosuke, and Marc Ratkovic. 2013. Estimating treatment effect heterogeneity in randomized program evaluation. Annals of Applied Statistics 7: 443-470.

Jijiao, Zhang, and Yin Peng. 2013. Ethnic migrants' employment and industry distribution in the cities of China. Review of Black Political Economy 40: 277-298.

Johnson, Emily N., and Gregory C. Chow. 1997. Rates of return to schooling in China. Pacific Economic Review 2: 101-113.

Li, Haizheng. 2003. Economic transition and returns to education in China. Economics of Education Review 22: 317-328.

Li, Haizheng, and Jeffrey S. Zax. 2003. "Labor supply in urban China." Journal of Comparative Economics 31: 795-817.

Li, Hongbin, Pak Wai Liu, and Junsen Zhang. 2007. Economic returns to Communist Party membership: Evidence from urban Chinese twins. Economic Journal 117: 1504-1520.

Li, Hongbin, Lingsheng Meng, Xinzheng Shi, and Wu. Binzhen. 2012. Does attending elite colleges pay in China? Journal of Comparative Economics 40: 78-88.

Li, Shi. 2002. Chinese household income project, [computer file]. ICPSR21741-v1. Ann Arbor: Inter-university Consortium for Political and Social Research [distributor], 2009-08-14. 10.3886/ICPSR2174.

Li, Shi, and Sai Ding. 2013. An empirical analysis of income inequality between a minority and the majority in urban China: The case of Ningxia Hui autonomous region. Review of Black Political Economy 40: 341-355.

Li, Shi, Chuliang Luo, Zhang Wei, and Ximing Yue. 2008. Appendix: The 1995 and 2002 household surveys: Sampling methods and data description. In Inequality and public policy in China, ed. Bjorn Gustafsson, Shi Li, and Terry Sicular, 337-353. New York: Cambridge University Press.

Long, Mark C. 2008. College quality and early adult outcomes. Economics of Education Review 27: 588-602.

Long, Mark C. 2010. Changes in the returns to education and college quality. Economics of Education Review 29: 338-347.

Maurer-Fazio, Margaret, James W. Hughes, and Dandan Zhang. 2010. A comparison and decomposition of reform-era labor force participation rates of China's ethnic minorities and Han majority. International Journal of Manpower 31: 138-162.

Mishra, Vinod, and Russell Smyth. 2010. "Economic returns to schooling for China's Korean minority," discussion paper 37/10, Department of Economics. Victoria: Monash University.

Moffitt, Robert A. 1999. Models of treatment effects when responses are heterogeneous. Proceedings of the National Academy of Sciences 96: 6575-6576.

Myers, Samuel L., Jr., Gao Xiaoyan, and Britt Cecconi Cruz. 2013. Ethnic minorities, race, and inequality in China: A new. perspective on racial dynamics. Review of Black Political Economy 40: 231-244. 
Rong, Xue Lan, and Tianjian Shi. 2001. Inequality in Chinese education. Journal of Contemporary China 10: 107-124.

The decision of the State Council on Accelerating the Development of National Education, Ministry of Education of the People's Republic of China, No. 46, 2015.

Tsai, Shu-Ling, and Yu Xie. 2011. Heterogeneity in returns to college education: Selection bias in contemporary Taiwan. Social Science Research 40: 796-810.

Wu, Jiaping. 2012. The rise of ethnicity under China's market reforms. International Journal of Urban and Regional Research 38: 967-984.

Wu, Xiaogang. 2010. Economic transition, school expansion, and educational inequality in China, 1990 - 2000. Research in Social Stratification and Mobility 28: 91-108.

Xiaowei, Zang, and Li Lulu. 2001. Ethnicity and earnings determination in urban China. New Zealand Journal of Asian Studies 3: $34-48$.

Xie, Yu. 2013. Population heterogeneity and causal inference. Proceedings of the National Academy of Sciences 110: 6262-6268.

Yee, Herbert S. 2003. Ethnic relations in Xinjiang: A survey of Uygur-Han relations in Urumqi. Journal of Contemporary China 12: 431-452.

Zang, Xiaowei. 2008. Market reforms and Han-Muslim variation in employment in the Chinese state sector in a Chinese City. World Development 36: 2341-2352

Zhong, Hai. 2011. Returns to higher education in China: What is the role of college quality? China Economic Review 22: 260-275.

Submit your manuscript to a SpringerOpen ${ }^{\circ}$ journal and benefit from:

- Convenient online submission

- Rigorous peer review

- Open access: articles freely available online

- High visibility within the field

- Retaining the copyright to your article

Submit your next manuscript at $\gg$ springeropen.com 